\title{
ANALYSIS OF PATIENT SATISFACTION WITH THE QUALITY OF HEALTH SERVICES AT NALA HUSADA DENTAL HOSPITAL (RSGM), HANG TUAH UNIVERSITY, SURABAYA
}

\author{
Budi Priyono
}

Universitas Hang Tuah, Surabaya, Indonesia

\begin{abstract}
RSGM Nala Husada Dental Hospital, Hang Tuah University, Surabaya is a center for service, development of science, dental and maritime technology as well as being the main teaching hospital for the UHT Faculty of Dentistry in order to improve people's oral and dental health. Supported by doctors, specialist dentists, pharmacists, medics, administrative personnel and adequate dental technology, it also functions to carry out dental and oral health services that prioritize treatment and patient recovery activities carried out in an integrated manner with efforts to improve and prevent as well as carry out referral efforts. Although service facilities are available Nala Husada Hospital, Hang Tuah University, Surabaya quite complete, but because of the many existing health institutions, it is very necessary to conduct research on the level of satisfaction of Nala Husada Hospital, Hang Tuah University, Surabaya. This study aims to provide input for parties Nala Husada Hospital, Hang Tuah University, Surabaya how the level of patient satisfaction with the quality of health services at Nala Husada Hospital, then what types of services need to be improved and instruments that can be used by the parties will be provided Nala Husada Hospital, to evaluate the quality of health services at Nala Husada Hospital, Hang Tuah University, Surabaya every year.
\end{abstract}

Keywords: Patient satisfaction, quality of dental and oral health services, RSGM Nala Husada

\section{INTRODUCTION}

\subsection{Background}

One of the second largest cities in Indonesia after DKI Jakarta is Surabaya City. It is not surprising that there are so many educational and entertainment centers in this city. Many residents from outside the city come to this city not only for vacation, but also to study. In addition, there are some of the best private campuses in Surabaya. One of them is the Hang Tuah University Surabaya. Based on the speech of the Head of L2DIKTI Wil VII Prof. Dr. Ir. Suprapto, DEA at the inauguration of UHT Professor Prof. Mokhamad Khoirul Huda, SH., MH on January 15, 2020 at GSG UHT, Hang Tuah University (UHT) is ranked 9th Best Higher Education in East Java. It is not wrong if a lot of students are interested in continuing their education at UHT Surabaya, Nala Husada Hospital, Hang Tuah University, Surabaya.

On March 24, 2018, Chief of Naval Staff (Kasal) Admiral TNI Ade Supandi, SE, MAP, as the supervisor of the Nala Foundation accompanied by the General Chairperson of Jalasenastri Ny. Endah Ade Supandi inaugurated the Nala Husada Dental Hospital (RSGM) Building, Hang Tuah University, Surabaya. Admiral TNI Ade Supandi in his speech said, RSGM Nala Husada UHT became an independent hospital under the auspices of the Nala Foundation, which was expected to become the leading Dental and Oral Hospital (RS) the only private hospital in Surabaya City. RSGM Nala Husada to a Teaching Hospital for health education institutions equipped with an Emergency Installation (IGD) for general public services.

Health is one of the main needs that people need in carrying out their daily activities. According to WHO (World Health Organization), health is a condition of physical, mental, and social welfare, and not only the absence of disease or weakness. Then according to Law No. 23 of 1992, health is a state of well-being of the body and soul, and socially which enables all people to live productively socially and economically. Based on these definitions, health is a physical and mental condition that must be maintained so that a society can live a prosperous life. According to Suharjana (2012), there are several ways to behave in a healthy life, including regulating food and diet, maintaining personal health, regulating rest, and exercising regularly.

However, over time, the number of available health services causes factors that 
affect the level of loyalty of a patient. Loyalty is a behavior aimed at routine service use and recommending others to use it. According to Musanto (2004), if customer satisfaction is higher, it can lead to profits because satisfied customers will continue to use services at the agency so that if customer satisfaction is high, customer loyalty will increase. Theoretically, the concepts of service quality, satisfaction, and loyalty are interrelated with one another, were service quality affects loyalty either directly or indirectly. According to Wendha, Rahyuda, and Atmosphere (2013), optimal service quality can be used as a company strategy to improve and retain customers who are expected to meet customer expectations so that it will create company satisfaction and loyalty because loyal customers are valuable assets to maintain continuity. company life in fierce market competition. According to Parasuraman, Zeithaml, and Berry (1988), there are five dimensions in measuring service quality, including tangible, reliability, responsiveness, assurance, and empathy.

Research on the level of customer loyalty in health institutions has been carried out several times including by Gunawan and Djati (2011) on service quality and patient loyalty at a private public hospital in Singaraja, Bali using multiple regression analysis. In this study, it was found that tangibles, empathy, reliability, responsiveness, and assurance had a partial effect on patient loyalty. Another study was by Puspitasari and Arifianty (2016) who examined the effect of service quality on patient satisfaction with complaints and loyalty of inpatients using the Kano model and concluded that the attributes that affect patient satisfaction with patient complaints and patient loyalty are attributes in the one category. dimensional, which is a good hospital layout,

Based on this background, it is necessary to do an analysis of the level of patient satisfaction with the quality of dental and oral health services in RSGM Nala Husada UHT Surabaya. As an evaluation of the quality of dental and oral health services so far inNala Husada Hospital. This evaluation will focus on gap analysis between the reality and expectations felt by dental and oral patients in using health services at RSGM Nala Husada UHT Surabaya. From this analysis, it can also be seen what types of services need to be improved so that in the future it is hoped that dental and oral health services in Nala Husada Hospitalcould be better. So that researchbased community service activities are carried out inRSGM Nala Husada UHT. This researchbased community service activity will also provide instruments that can be used by
partiesRSGM Nala Husada UHT., to evaluate the quality of dental and oral health services at RSGM Nala Husada UHT every year.

\subsection{Formulation of the problem}

The formulation of the problem in this study are:

a. What are the characteristics of UHT Nala Husada Hospital patients based on descriptive statistical analysis?

b. What is the reality and expectations of patients for health services at the UHT Nala Husada Hospital?

\subsection{Expected Objectives, Benefits, Impact of Activities}

The purpose of this activity is to evaluate and analyse patient satisfaction RSGM Nala Husada UHT based on statistical methods.

a. Knowing patient characteristics based on descriptive statistical analysis of patients RSGM Nala Husada UHT and behaviour b. Describe the relationship between the level of patient satisfaction and the quality of health services at RSGM Nala Husada UHT.

\section{MATERIAL AND METHODS}

\subsection{Research Method}

This activity will provide benefits for parties RSGM Nala Husada UHT and the local community. RSGM Nala Huasada UHT will benefit from the results of the analysis carried out, as a reference for improvising and making further policies related to health services. When RSGM Nala Husada UHT able to improve the performance of health services in accordance with community needs, this activity will provide benefits to the community by making it easier for people to get quality health services.

The impacts expected from this activity include short-term impacts, medium-term impacts and long-term impacts. The short-term impact expected from the analysis of this activity can be used as input for Nala Husada Hospital UHT in improving the performance of health services. This will encourage the realization of the expected medium-term impact, namely that more and more people will use and experience the benefits of dental and oral health services in Indonesia. Nala Huasada Hospital UHT. In the end, as a long-term impact, it is hoped that this activity will be able to reduce and prevent the number of sick people. The Nala Husada Dental and Oral Hospital (RSGM) of Hang Tuah University Surabaya, was built in 2002, precisely in East Surabaya, on Arif Rahman Hakim Street Number 150 has the function of implementing dental and oral health services that prioritize treatment and recovery of patients which are 
carried out in an integrated manner with efforts to improve and prevent as well as carry out referral efforts. The Nala Husada Dental Hospital (RSGM) of Hang Tuah University Surabaya is supported by adequate doctors, dentists, pharmacists, medical personnel, administrative personnel and dental technology.

The vision, mission and motto of the Nala Husada Dental Hospital (RSGM) of Hang Tuah University Surabaya are as follows.

\subsection{Vission and Mission Nala Husada UHT Surabaya \\ 2.2.1 Vission}

The Nala Husada Dental and Oral Hospital (RSGM) is a center for service, development of dental science, technology for dentistry and maritime affairs as well as being the main teaching hospital for the UHT Faculty of Dentistry to improve the oral health of the community.

\subsubsection{Mission}

The Missions are:

a. Providing quality and affordable dental and oral health services.

b. Increasing the professionalism of hospital human resources that are highly competitive.

c. Complete hospital facilities and infrastructure that are safe and comfortable for staff, patients and other visitors.

d. Improve Hospital management that is flexible, effective and efficient.

e. Take an active role in improving the degree of oral health, especially for people in coastal areas.

f. Carrying out education, research for students of the Faculty of Dentistry, Hang Tuah University, or other dental and oral health education institutions at the Diploma level (D-III and D-IV).

g. Always prioritize quality and patient safety in every dental and oral health service.

Nala Husada Dental and Oral Hospital (RSGM), as an independent dental and oral health institution under the auspices of the Nala Foundation, it is the only leading private Dental and Oral Hospital in the city of Surabaya.

RSGM Nala Husada Teaching Hospital for health education institutions has 8 (eight) services, namely:
a. Integration Clinic,
b. VIP Dental Clinic,
c. Emergency Department (UGD),
d. Inpatient,
e. Major and Minor Surgical Units,
f. Dental Laboratory,

\section{g. Dental Radiology \\ h. Ambulance Unit.}

Operating hours is a kind of Integration Clinic 08.00 until 15.00, VIP Dental Clinic 08.00 until 20.00 and emergency room 24 hours, with many services all of which are intended for the convenience of dental and oral patients. Therefore, RSGM Husada Nala is required to be able to provide good quality service so that customer satisfaction, in this case is the patient, especially dental and oral patients, can be maximally achieved so as to increase customer loyalty to (RSGM) Nala Husada UHT Surabaya

\subsection{Factors in Health Care}

Service quality and satisfaction with patient loyalty at the UHT Nala Husada Hospital are factors that theoretically are conceptually and rationally related to loyalty either directly or indirectly.

\subsubsection{Service quality}

Service quality is a comparison between customer expectations about the service that must be received and the perception of the service that has been received. According to Parasuraman, et al. (1988), there are five dimensions in measuring service quality, including:

a. Tangible dimensions (direct evidence) Tangible means physical evidence, which includes appearance of physical facilities, equipment, staff and materials owned by the organization in attracting those requiring these services. The existence of a good Tangible in an organization is needed to attract people to come to that place. In public services, physical evidence includes available parking spots, interior arrangement of service spaces, cleanliness of service spaces, comfort of service rooms, availability of telephone lines for communication, neatness of employee appearance, availability of information about certain services (brochures, forms, billboards, etc).

b. Dimensions of Empathy

Empathy means concern and attention (attention) of employees or business owners to all communities, including the ease of making good relationships, personal attention, and understanding the needs of society. This means that every employee of the company must be able to pamper the user, pay attention to the user, and make the user the king who must be served well and make the community an asset of the company's assets that must be maintained and increased in power. In public service empathy includes the ease with which staff can be contacted and met by the 
community, staff efforts to provide explanations to the community in making easy to understand language, and staff efforts to understand community needs.

\section{c. Reliability dimension}

Reliability means the ability of a company or business entity to provide services as promised (providing service a promised), accurately (accurately), can be trusted, and consistent. This means requiring company personnel to work appropriately in providing services to the public in accordance with the promised time and accuracy of opening hours or accuracy of closing hours. In public service, the company's capabilities include the ability of staff to provide appropriate advice so that they can help the community solve problems, the ability of staff to deal with errors that arise during the service delivery process, the ability of staff to provide information needed by the community accurately.

\section{d. Responsiveness Dimension}

Responsiveness or responsiveness means being responsive to the needs of the community and prompt in providing services. This means requiring company personnel to work quickly and agile or to be happy to assist the community in determining service options. In public service responsiveness includes the willingness of staff to provide services needed by the community quickly, the ability of staff to respond to community requests quickly.

e. Assurance Dimension (Attention)

Insurance means guaranteeing and providing a sense of security to people who need the support of adequate knowledge, politeness (courtesy), a professional attitude, and self-confidence. People who are in doubt need to be convinced. This means, it requires every company to educate its employees to have skills, both technical and knowledge, adequate and polite in providing services. The community is relatively sensitive to employee politeness, meaning that if employees do not know or are not polite in providing services, the community will turn to competing companies.
In public services, assurance includes the knowledge of staff in addressing community needs, friendliness and courtesy of staff in serving the community, the trustworthiness of staff.

\subsubsection{Satisfaction}

Satisfaction is the feeling obtained from the evaluation process between the results received and what is expected. If the results are not as expected, the customer will be disappointed. If it is in line with expectations, the customer will be satisfied. If the results received exceed expectations, the customer will feel happy. Satisfied customers will continue to purchase or use services or return, while customers who are dissatisfied will stop purchasing or using services and will sometimes tell their friends about their dissatisfaction. Therefore, a smart company or institution will guarantee customer satisfaction at every stage of the purchase or service.

\section{$2.4 \quad$ Loyalty}

Loyalty is a behavior aimed at routine purchases and recommending others to buy in. According to this definition, it can also be interpreted that loyalty in the health sector is a behavior shown by the return of a patient when he is sick at a certain health institution and recommending other people to seek treatment at that place.

According to Griffin (2001), the characteristics of loyal customers include:

1. Make repeated purchases on a regular basis.

2. Buy cross-line products and services.

3. Shows immunity to pull from competitors. Referring to others.

\subsection{Conceptual Framework}

According to Lovelock (2005: 98) The relationship between instrument dimensions and patient satisfaction can be systematically described into 5 (five) dimensions as follows:

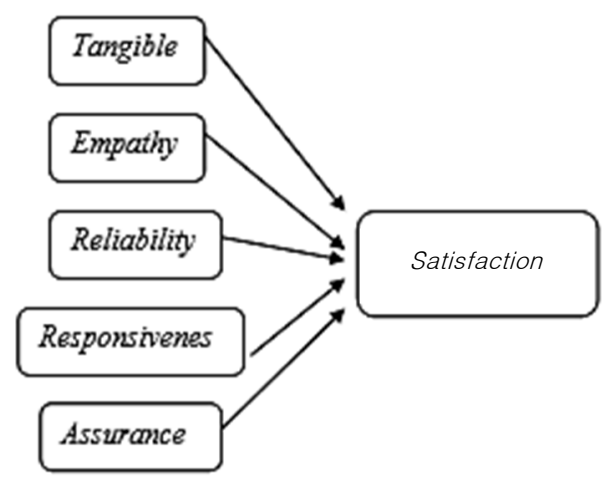

Figure 1. The relationship between instrument dimensions and patient satisfaction 


\section{RESEARCH METHODS}

\subsection{Research design}

This research activity was organized in collaboration with the Nala Husada Dental Hospital Hang Tuah University, Surabaya. RSGM Nala Husada UHT is a dental and oral health service, which not only serves UHT students but also the general public. The Nala Husada Dental Hospital of Hang Tuah University Surabaya also functions as a service center, development of dental science, technology and maritime medicine as well as being the main teaching hospital for the UHT Faculty of Dentistry to improve public oral and dental health, supported by doctors, specialist dentists, pharmacists, medical personnel, administrative personnel and adequate dental technology.

To ensure the achievement of this community research program, it is necessary to describe the potential of research partners as follows.

a. The existence of employees or health workers who are enthusiastic about providing the best service to the community;

b. There is support from the Director (RSGM) Nala Husada UHT in providing information needed by the team and granting permission to carry out surveys in (RSGM) Nala Husada UHT (indicated by a statement letter that is willing to be a community service partner);

c. The officers' seriousness in making service improvements to improve the quality of health services in (RSGM) Nala Husada UHT;

d. There is a communication forum between officers who often share in order to improve the quality of health services to the public.

\subsection{Place and time of research}

This research was conducted from November 2019 to June 2020. The data used in this study are primary data through surveys of patients in Nala Husada Hospital, Hang Tuah University, Surabaya.

\subsection{Population and Sample \\ 3.3.1 Population}

Population according to Indriantoro and Supomo (2002) is a group of people, events, or everything that has certain characteristics. The population used in this study were all patients in Nala Husada Hospital, Hang Tuah University, Surabaya.

\subsubsection{Sample}

Determination of the number of samples using probability sampling techniques with systematic sampling method. The number of patients who came to RSGM Nala Husada, Hang Tuah University, Surabaya based on the RSGM Management Information System in October 2019 was 1756 people. The results of the preliminary survey, the $p$ value was obtained (the probability of the patient returning for treatment), with 30 respondents and it was found that as many as 20 people would return when sick $(p=0.7)$ and 10 people answered that they would not or would not necessarily return. when sick $(q=0.3)$. The following is a calculation of the number of samples obtained using an estimated error limit of $5 \%$.

$$
\begin{aligned}
& n=\frac{N p q}{(N-1) D+p q} \text {, with } D=\frac{B^{2}}{4} \text { and } \\
& q=1-p \\
& n=\frac{(1756)(0,7)(0,3)}{(1756-1) \frac{0,05^{2}}{4}+(0,7)(0,3)}=282,169 \approx 283 \\
& \text { with, } \mathrm{N}=\text { Number of patient population in } \\
& \text { October } 2019 . \\
& n=\text { Number of patient samples } \\
& B=\text { Estimation error limit } \\
& p=\text { Probability of loyal / returning } \\
& \text { patients (preliminary survey } \\
& \text { results) }
\end{aligned}
$$

So that the number of samples who became respondents in this study were at least 283 respondents with the length of the observation interval $(\mathrm{k})$ as follows.

$$
k=\frac{N}{n}=\frac{1756}{283}=6,2049 \approx 7
$$

This means that a survey will be conducted on the 7th person in each respondent by determining the first person is random.

\subsection{Data Analysis Techniques}

The data analysis technique used in this research is a technique with a quantitative approach that uses a statistical approach. Thus, the stages carried out in conducting data analysis are as follows:

\subsubsection{Descriptive Statistics}

Descriptive statistics are methods related to the collection and presentation of a data set so as to provide useful information. Descriptive statistics provide information only about the data at hand and do not draw any inferences or conclusions about the larger parent dataset. Included in the descriptive 
statistics category are the arrangement of tables, diagrams, graphs, etc. (Walpole, Ronald E. 1995).

\subsubsection{Average}

Average is calculation by dividing the number of data values by the amount of data. The average formula is as follows:

$$
=\frac{1}{n} \sum_{i=1}^{n} X_{i}
$$

information:

$$
\begin{aligned}
\bar{X} & =\text { average data } \\
\mathbf{X}_{\mathbf{i}} & =\mathrm{j}^{\text {th }} \text { data } \\
n & =\text { amount of data }
\end{aligned}
$$

\subsubsection{Variance}

Variance is the average value of the square of the deviation.

$$
s^{2}=\frac{\sum_{i=1}^{n}\left(x_{i}-\overline{\mathrm{x}}\right)^{2}}{n-1}
$$

information:

$s^{2}=$ size of spread (variant)

$n=$ amount of data

\subsubsection{Minimum and Maximum}

The minimum value is the lowest value of the observed data set and the maximum value is the highest value of the observed data set. (Walpole, 1995).

\subsection{Gap Analysis}

In both business and service sector, gap analysis is used to determine what steps need to be taken to move from a current state to a desired state or a desired future state. Many people call this needs and gap analysis, needs assessment or just needs analysis. Gap analysis can also be interpreted as a comparison of actual performance with potential or expected performance. As a method, gap analysis is used as a business or service evaluation tool that focuses on the current performance gap of the company or institution with the performance that has been previously targeted. This analysis also identifies what actions are needed to reduce gaps or achieve expected performance in the future.

The service quality model to determine the level of customer satisfaction achievement developed by Parasuraman, Berry and Zeithaml in an effort to identify gaps, there are 5 types of gaps, namely:

a. gap about knowing consumer expectations of service,

b. gaps about having a design and service standards right,

c. gaps about providing services based on standards,

d. gaps about providing services in accordance with promises, and

e. gaps about differences in perceptions with consumer expectations of service.

Research conducted by Parasuraman, VA Zeithaml and Berry (1988) produced a service quality gap model to achieve customer satisfaction in 5 steps, as in Figure 3.1 below (Febriyanto, 2011).

A tool that can be used to see both service quality and product quality is a Cartesian diagram. Cartesian diagrams are used to analyse gaps in customer expectations and reality. How to do a Gap analysis using a Cartesian diagram, which is adding up per factor in each sample from the reality column denoted by $X$ and the expectation column denoted by $Y$, then the average value per factor is calculated from the reality column $\bar{X}$ and hope $\bar{Y}$. To obtain the boundary plot line of the Cartesian diagram, the mean of $\bar{X}$ and $\bar{Y}$,

\begin{tabular}{|c|c|c|c|c|c|c|c|c|}
\hline \multirow[b]{3}{*}{ Sample i } & \multicolumn{4}{|c|}{ Reality $(\mathbf{X})$} & \multicolumn{4}{|c|}{ Hope $M$} \\
\hline & \multicolumn{4}{|c|}{ The jh factor } & \multicolumn{4}{|c|}{ The jh factor } \\
\hline & 1 & 2 & $\cdots$ & $\boldsymbol{k}$ & 1 & 2 & $\cdots$ & $k$ \\
\hline 1 & $x_{11}$ & $x_{12}$ & $\cdots$ & $x_{1 k}$ & $Y_{11}$ & $Y_{12}$ & $\cdots$ & $Y_{1 k}$ \\
\hline 2 & $x_{21}$ & $x_{22}$ & $\cdots$ & $X_{2 k}$ & $Y_{21}$ & $Y_{22}$ & $\cdots$ & $Y_{2 k}$ \\
\hline$\vdots$ & $\vdots$ & $\vdots$ & $\cdots$ & $\vdots$ & $\vdots$ & $\vdots$ & $\cdots$ & $\vdots$ \\
\hline$n$ & $X_{n 1}$ & $x_{n 2}$ & $\cdots$ & $X_{n k}$ & $Y_{n 1}$ & $Y_{n 2}$ & $\cdots$ & $Y_{n k}$ \\
\hline & $X_{1.1}$ & $x_{2}$ & $\cdots$ & $x_{k}$ & $Y_{1}$ & $Y_{2}$ & $\cdots$ & $Y_{k}$ \\
\hline
\end{tabular}
which is denoted by $\overline{\bar{X}}$ and $Y$ (Dharma, 2016). The table of expectations and reality is presented in Table 1 as follows:

Table 1. Expectations and Realities Column 
The calculation of the values required to make a Cartesian diagram is as follows:

$$
\begin{aligned}
& \bar{X}_{j}=\frac{X_{j}}{n} ; j=1,2, \ldots, k \\
& \bar{Y}_{j}=\frac{Y_{j}}{n} ; j=1,2, \ldots, k
\end{aligned}
$$

$$
\begin{aligned}
& \overline{\bar{X}}=\frac{\overline{X_{1}}+\overline{X_{2}}+\ldots+\overline{X_{k}}}{k} \\
& \overline{\bar{Y}}=\frac{\overline{Y_{1}}+\overline{Y_{2}}+\ldots+\overline{Y_{k}}}{k}
\end{aligned}
$$

\section{The Cartesian diagram is divided into 4 quadrants as follows:}

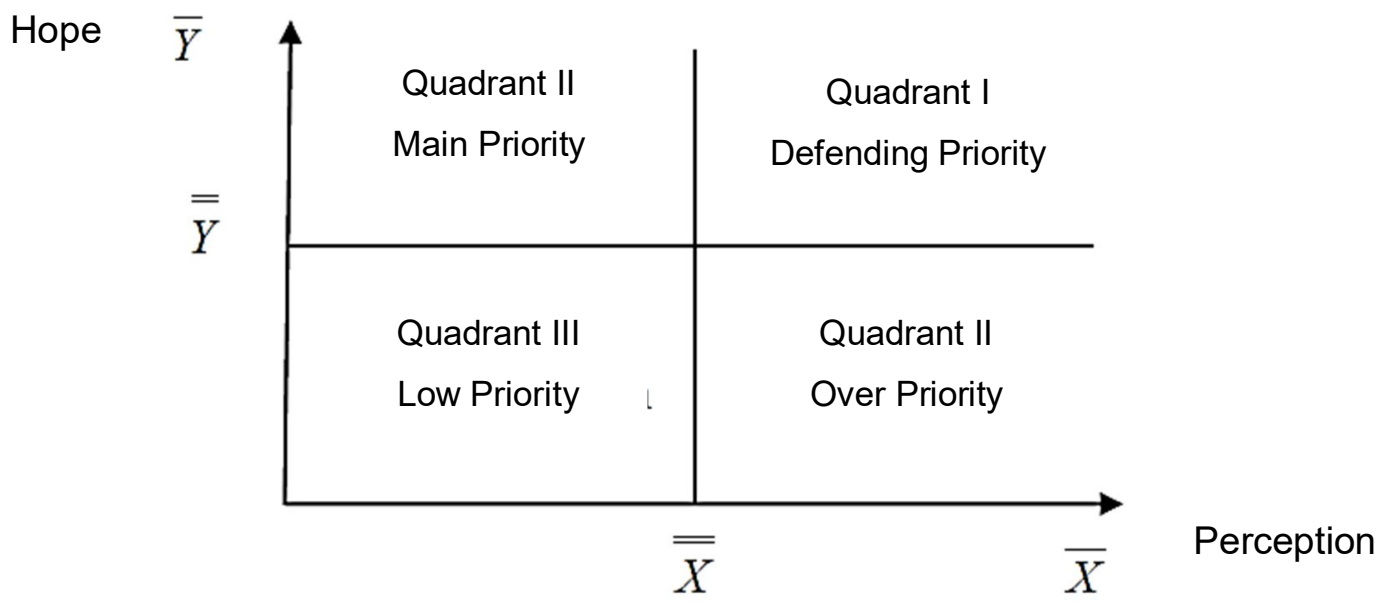

Figure 2. The Cartesian Diagram of Expectations and Realities

\section{ANALYSIS AND DISCUSSION}

The initial stage that must be completed is to conduct a core survey with all valid and reliable questions, see whether the core survey results are valid and reliable or not, describe the characteristics of respondents, and conduct a gap analysis to determine the level of patient satisfaction with the quality of health services at RSGM Nala Husada UHT, Surabaya.

\subsection{Validity and Reliability Test Results of the Core Satisfaction Survey at RSGM Nala Husada UHT}

The validity and reliability tests were analyzed using available measuring instruments, namely a questionnaire regarding the factors forming the level of patient satisfaction at RSGM Nala Husada UHT. The validity test was carried out on each of the question instruments on the patient satisfaction data at the UHT Nala Husada Dental Hospital both in terms of reality and patient expectations. The validity test is used to measure the accuracy of the indicators that affect the level of patient satisfaction at the UHT Nala Husada Hospital. The validity test in this study is as follows.

Hypothesis:

$\mathrm{HO}=$ Invalid statement.
$\mathrm{H} 1=$ Statement is valid.

$\mathrm{HO}$ is rejected if the $\mathrm{p}$-value $<\alpha$ where the value or value of the correlation coefficient is greater than $r$ table, namely $0.119, \alpha=0.05$.

The results of the validity test on the satisfaction survey data at the UHT Nala Husada Dental Hospital showed that the questions on patient satisfaction at the UHT Nala Husada Hospital (reality) as a whole had a P-value less than 0.05 . So, it can be said that the questions used in the patient satisfaction survey at RSGM Nala Husada UHT are valid. Furthermore, the validity test was carried out on the patient satisfaction data of the UHT Nala Husada Hospital (Hope).

The validity test of the data from the satisfaction survey results at the UHT Nala Husada Dental Hospital shows that the questions for patient satisfaction at the UHT Nala Husada Hospital (Hope) all questions have a P-value less than 0.05 and the correlation coefficient is greater than 0.119 so that the question items for Patient satisfaction data at RSGM Nala Husada UHT (Hope) is valid. After the validity test is carried out, then an analysis will be carried out regarding the reliability test.

The reliability test is used to determine the indicators that affect the level of patient satisfaction of the UHT Nala Husada Hospital 
and can be used more than once or not. Reliability testing in this study is as follows.

Hypothesis:

$\mathrm{HO}=$ Unreliable statement

$\mathrm{H} 1$ = reliable statement.
Critical area: $\mathrm{HO}$ is rejected if:

$$
\alpha_{\text {cronbach's }}>r_{\text {tabel }}
$$

where is the value

$$
r_{\text {tabel }}=r_{(0,05 ; 268)}=0,119
$$

The test is drawn in this below table.

Table 2.Validity Test Results of Transformational Leadership Variables

\begin{tabular}{ccc}
\hline Variable & $\begin{array}{c}\text { Cronbach's Alpha } \\
\text { Value }\end{array}$ & $\begin{array}{c}\text { R- } \\
\text { table }\end{array}$ \\
\hline Satisfaction (Reality) & 0.752 & 116. \\
\hline Satisfaction (Hope) & 0.753 & 116 \\
\hline
\end{tabular}

Table 2 shows the results of the reliability test on the results of the reality survey and the expectation survey at the RSGM Nala Husada UHT, based on the Cronbach's Alpha value, namely 0.752 for the reality indicator and 0.753 for the hope indicator, these values are greater than the R-table value of 0.116 . it can be said that the statement is reliable with very high criteria so that a decision can be made that the statements are correct and are used for research.

\subsection{Characteristics of Demographic Data on the Results of the Satisfaction Survey at RSGM Nala Husada UHT}

The characteristics of the demographic data from the core satisfaction survey results at RSGM Nala Husada UHT are measured through a pie chart or barchart for data that has a categorical measurement scale, and uses concentration / distribution in the form of averages, minimum and maximum values, and mode for data that has a scale. numerical measurement. The data characteristics aim to provide a visual description of the sample of respondents in the satisfaction survey at the UHT Nala Husada Hospital in 2019.

In the satisfaction survey at RSGM Nala Husada UHT, population demographics in the form of gender were used to determine the proportion of male and female patients who received treatment at UHT Nala Husada Dental Hospital. The description of the proportion of sex can be explained in Figure 3 where more than half of the samples surveyed at the UHT Nala Husada Dental Hospital were female. This can be seen through the large percentage of people who are female, namely $53 \%$, but this number has a similar difference with the male gender, which is $47 \%$. So it can be said that the gender proportion of satisfaction survey respondents at the UHT Nala Husada Hospital is almost balanced.

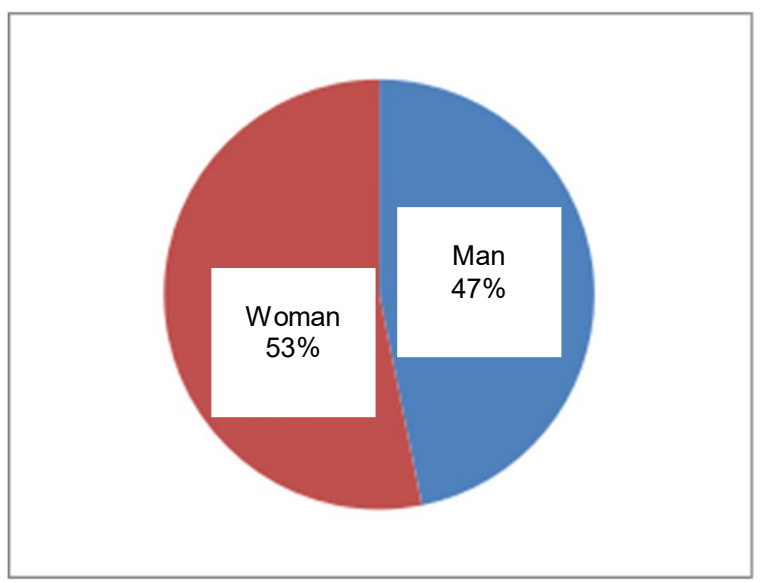

Figure 3. Characteristics of Data Based on Gender

Age characteristics are used to see the age proportion of respondents at UHT Nala Husada Dental Hospital in 2019. Characteristics of respondents at UHT Nala Husada Dental Hospital can also be explained based on the age range that visited UHT Nala Husada Hospital which is explained through the minimum and maximum age values average, and center the data using the mode value. It is known that the average of respondents who visited RSGM Nala Husada UHT was 27 years old with the youngest being 15 years old being respondents who were still in junior high school level while the oldest was 74 years old, namely retired respondents. This shows that the respondents who visited the RSGM Nala Husada UHT consisted of various ages. However, the age group that most frequently visited the UHT Nala Husada Dental Hospital were 18 year old students. Meanwhile, the characteristics of the education level and type of work of the respondents who visited the RSGM Nala Husada UHT can be explained in Figure 4 and Figure 5. 


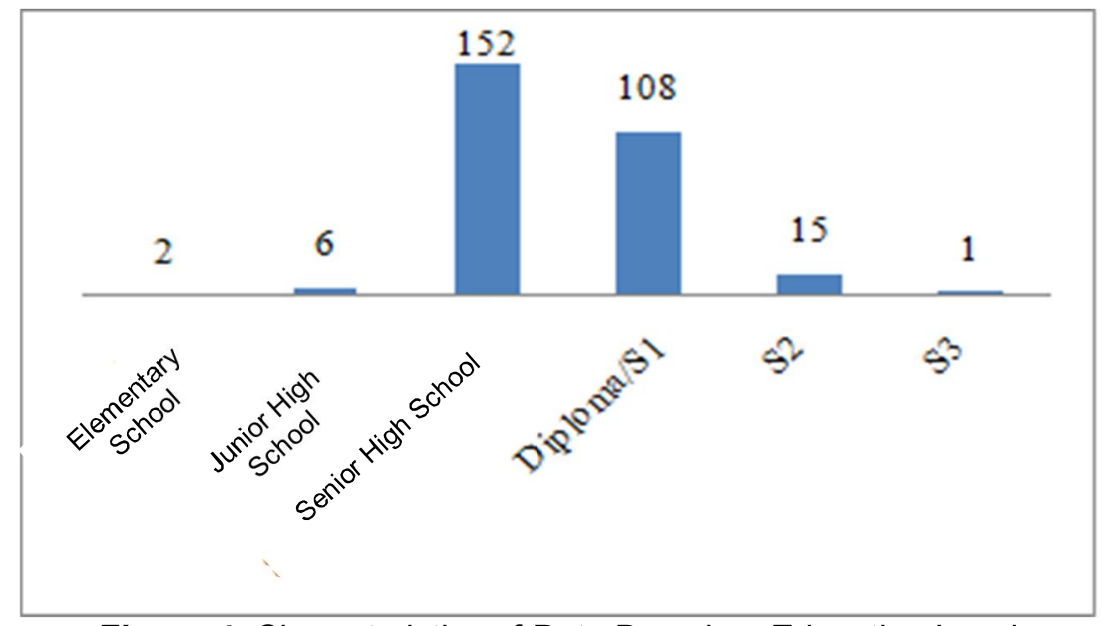

Figure 4. Characteristics of Data Based on Education Level

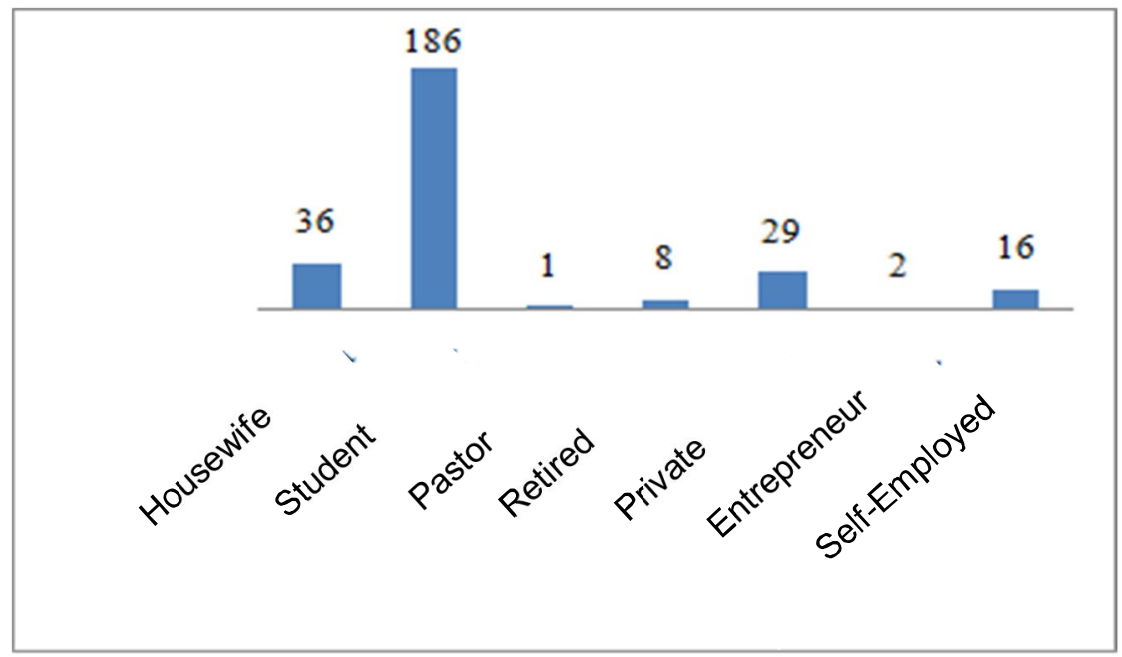

Figure 5. Job Based Data Characteristics

Based on the level of education described in Figure 4 and the type of work in Figure 5, it is said that according to the number of respondents who visited RSGM Nala Husada UHT based on age proportions. Which in the proportion of age, respondents who visited the most visits to RSGM Nala Husada UHT were students aged 18 years, while based on the level of education, it was found that 152 high school students made the most visits to RSGM Nala Husada UHT, as well as S1 / DIII students. the second highest number after high school students. This can also be explained through the type of work that visits the highest number of students.

However, if seen as a whole, the respondents who visited the UHT Nala Husada Dental Hospital have an even level of education from SD / Ml to S3. Likewise, for the types of work of respondents who consist of various groups such as students / students, civil servants, self-employed and others as described in Figure 5.
4.3 GAP Analysis on the Results of the Satisfaction Survey at the UHT Nala Husada Hospital in 2019.

In this study, GAP analysis is aimed at all dimensions that affect the level of patient satisfaction at the UHT Nala Husada Dental Hospital. Apart from all dimensions, GAP analysis is also carried out on the indicators contained in each dimension. Many dimensions used in this analysis consist of tangible, empathy, reliability, responsiveness, assurance, and indicators of patient satisfaction.

\section{a. GAP Analysis on All Dimensions that Affect Patient Satisfaction at the 2019 UHT Nala Husada Hospital}

The questions used in this survey are 77 questions with 5 dimensions and 1 patient satisfaction indicator. In the Tangible dimension there are 13 questions, 9 questions for the Empathy dimension, 6 questions for the Reliability dimension, 10 questions for the Responesiveness and Assurance dimensions and 29 questions for the level of patient satisfaction. Based on the five dimensions and 
one satisfaction indicator, the results of the distance / GAP analysis can be carried out as described in Figure 7.

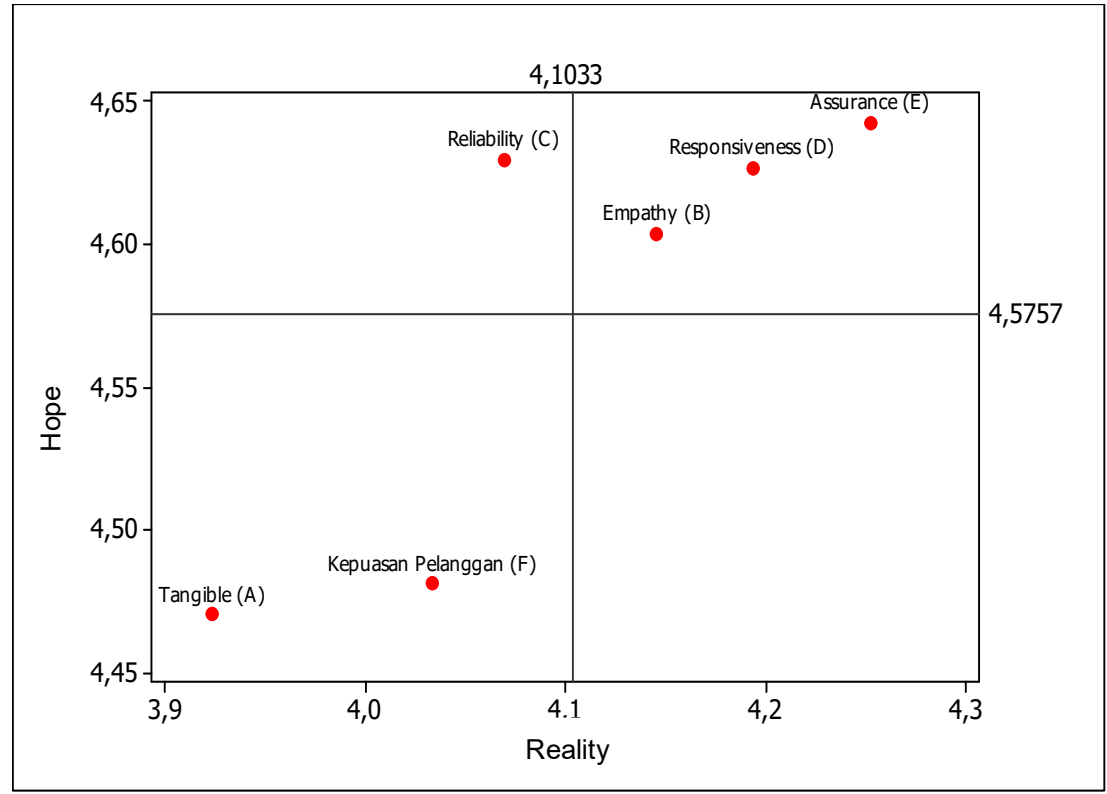

Figure 6. GAP Analysis in All Dimensions

Based on Figure 6 it is known that the dimensions Empathy, Responsiveness, and Assurance is in quadrant II, which is said to be the reality and expectation of UHT Nala Husada Hospital patients. For this reason, the three dimensions must be maintained for service performance because these dimensions are said to have met the satisfaction level of the polyclinic because the expectations are well fulfilled. Furthermore, the Reliability dimension is in quadrant I, where the expectations of the patients at RSGM Nala Husada UHT are high but reality is low. For this reason, it is necessary to improve services regarding the reliability of officers and doctors at UHT Nala Husada Hospital.

b. GAP Analysis on Tangible Dimensions that Affect Patient Satisfaction at UHT Nala Husada Hospital in 2019

In the Tangible dimension, there are 13 question indicators regarding patient satisfaction at the UHT Nala Husada Hospital. Which these indicators consist of satisfaction with various types of facilities at RSGM Nala Husada UHT such as parking lots, treatment rooms, toilets and so on. The results of the distance / GAP analysis on the Tangible dimension can be explained in Figure 8 .

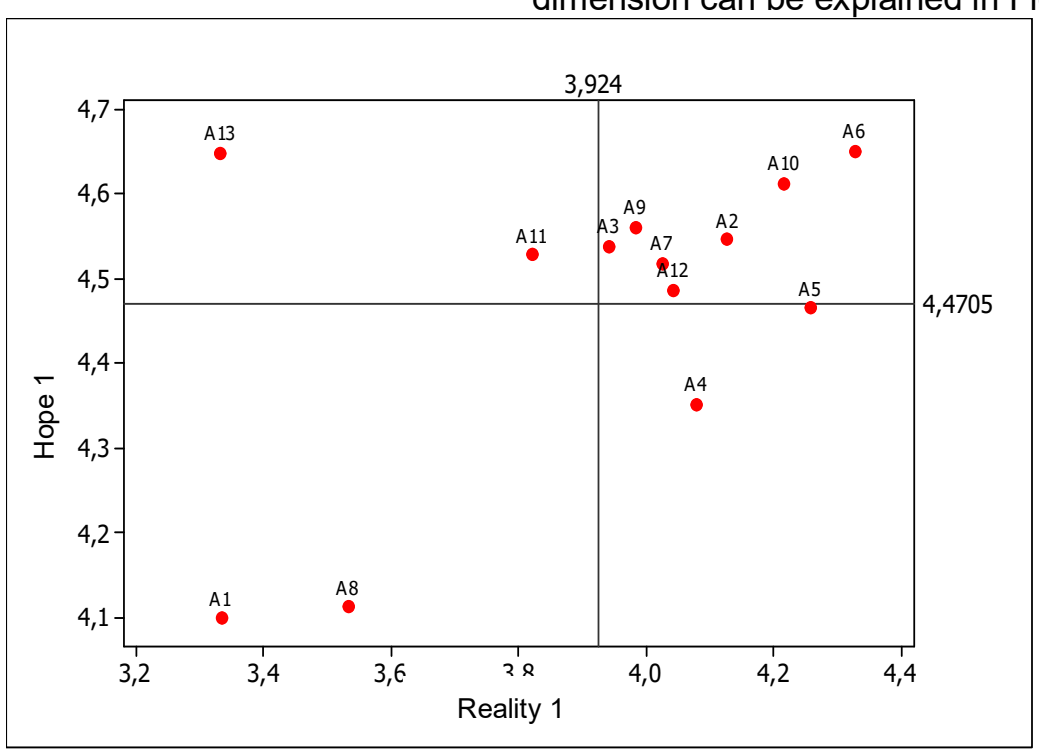

Figure 7. GAP Analysis on Tangible Dimensions 
Figure 7 explains that the indicators in quadrant II which have reality and high expectations are seven indicators including satisfaction regarding the Nala Husada UHT Hospital building which is neat, clean, and comfortable (A2), the environment around RSGM Nala Husada UHT is clean and beautiful (A3), a clean, comfortable and safe waiting room (A6), an adequate number of waiting room seats (A7), clean and comfortable toilets (A9), a comfortable and clean doctor's care room (A10), and convenient pharmacy waiting room (A12). It can be said that the RSGM Nala Husada UHT was able to provide comfort and cleanliness in terms of the environment of the UHT Nala Husada Hospital as well as the waiting room and place of care for patients.

However, sometimes the indicators that should be the focus of the RSGM Nala Husada UHT to be further improved are satisfaction with a clear signpost (A11) and the number of doctors who are sufficient to treat patients (A13) because patients have high expectations but in reality, it is low. Meanwhile, the indicator for a large parking area (A1) and entertainment in the waiting room (A8) is in quadrant III, meaning that reality is low but expectations are also low. This shows that patients do not realize the importance of a large parking area to support the number of patients at the UHT Nala Husada Hospital and entertainment in the waiting room which can be used to reduce boredom. So, it is necessary to continuously provide information about the importance of these indicators to support patient satisfaction at the UHT Nala Husada Hospital.

c. GAP Analysis on the Dimensions of Empathy I Empathy that Affects Patient Satisfaction at UHT Nala Husada Hospital in 2019

The Empathy dimension is used to measure the level of empathy of officers or doctors at UHT Nala Husada Hospital. In this survey, 9 indicators were used which broadly measured the means of communication, attention, and support of officers and doctors at RSGM Nala Husada UHT. The results of the GAP analysis for the Empathy dimension are described in Figure 8.

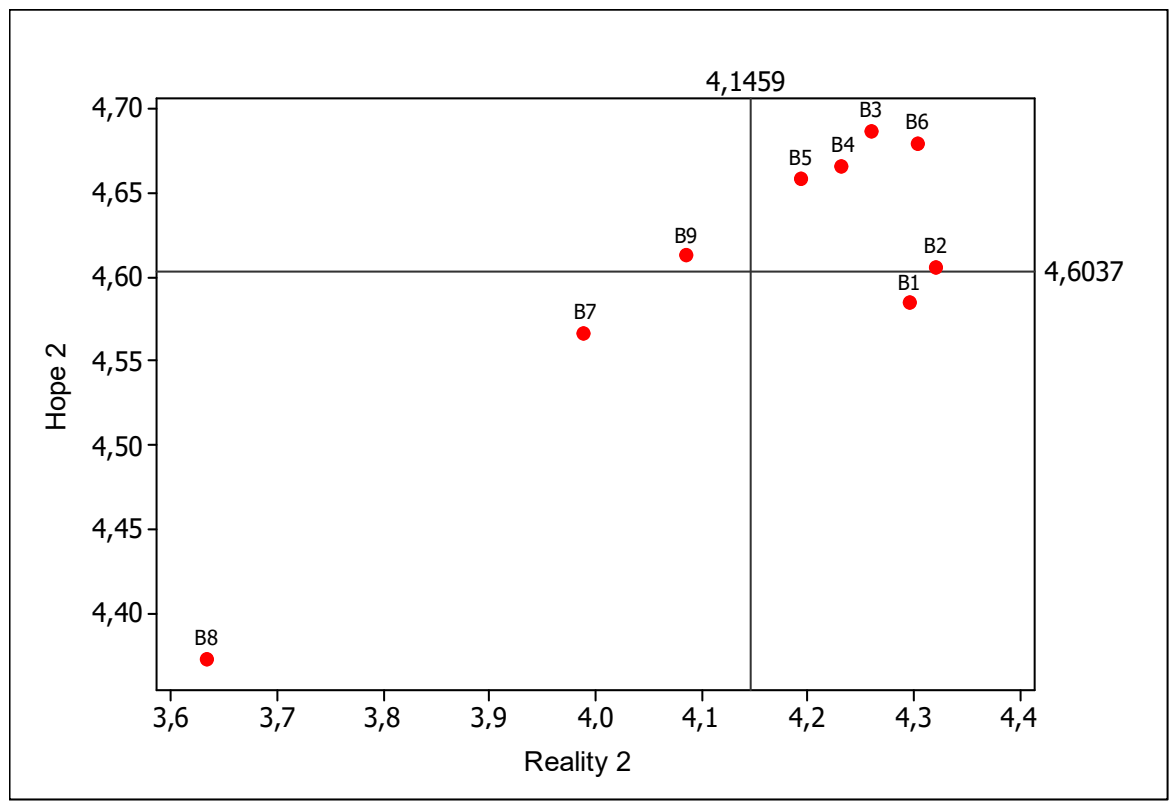

Figure 8. GAP Analysis on Empathy / Empathy Dimensions

Figure 8. explains the indicators of officers serving friendly and polite (B9) which are in quadrant $\mathrm{I}$, which means high expectations but low reality. This shows that the UHT Nala Husada Dental Hospital patients have high expectations about the friendliness of the UHT Nala Husada Hospital officers, for that the UHT Nala Husada Dental Hospital must make an indicator. Empathy in the form of official service methods as a top priority that need to be addressed

Furthermore, the indicators that are included in quadrant II are high expectations and high reality, which are indicators of doctors who do not differentiate between patients (B2), doctors pay attention to patient conditions and complaints (B3), doctors communicate sufficiently with patients (B4), doctors conduct adequate examination with the patient (B5), and the doctor communicates in a friendly and 
polite manner (B6). This shows that patients have high expectations for the way doctors know patients, as well as supported by high reality, so it is said that good ethics from doctors at RSGM Nala Husada UHT in knowing patients is an indicator whose performance needs to be maintained because it has met patient satisfaction at Nala Husada Hospital, UHT.

d. GAP Analysis on Reliability Dimensions that Affect Patient Satisfaction at RSGM Nala Husada UHT 2019
Reliabilityis a dimension that measures the reliability of doctors and staff at the UHT Nala Husada Hospital which consists of 6 indicators. The reliability in this survey consists of service schedules, training procedures, thoroughness, professionalism, and doctor's responsibility in providing services to patients. Based on Figure 9, the GAP analysis on the Reliability dimension is explained.

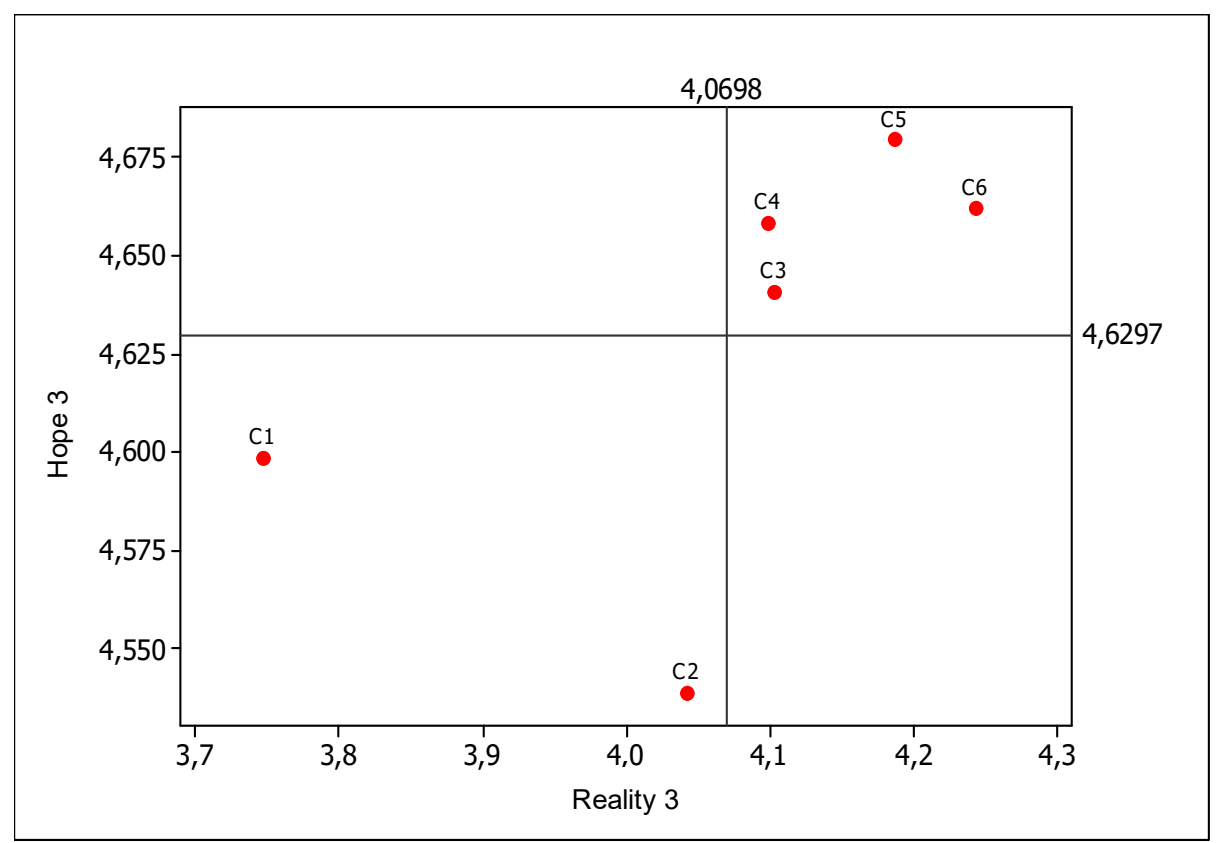

Figure 9. GAP analysis on the dimension of reliability.

GAP analysis on the Reliability dimension shows that there are no indicators in quadrant $I$ so it is said that there are no indicators that should be the main focus to be addressed. This is also shown by the number of indicators that are in quadrant II, which are indicators with high expectations and supported by high reality, including indicators that doctors are careful in examining (C3), doctors provide the right diagnosis (C4), patients trust the doctor's ability to serve. the patient (C5), and the doctor is responsible for the treatment suffered by the patient (C6). The existence of several indicators in quadrant II shows that patients have high expectations of the ability of doctors at UHT Nala Husada Hospital and this is followed by high reality,

Meanwhile, the indicator for the appropriate treatment service schedule (C1) and the appropriate treatment service procedure has a low reality but also low patient expectations. This shows that patients do not know the importance of timeliness of service and structured service procedures. So, it is necessary to provide insight into the importance of these two indicators.

e. GAP Analysis on Responsiveness Dimensions / Accuracy that Affects Patient Satisfaction at RSGM Nala Husada UHT 2019

The fourth dimension used to measure the level of patient satisfaction at RSGM Nala Husada UHT is Responsiveness / Responsiveness. This dimension consists of 10 indicators, including measuring the readiness of officers in serving patients, the interaction of doctors in asking complaints, providing opportunities to ask questions, and providing quick and precise action in accordance with applicable procedures.

Based on Figure 10 regarding the GAP analysis on the Responsiveness dimension, it is known that patient expectations are quite high on the indicator that doctors are able to serve patients quickly and precisely, but the reality is low. So that this indicator needs to be the main focus of RSGM Nala Husada UHT to be further improved, so that patient 
expectations regarding the accuracy of doctors in providing services to patients can be fulfilled. On the other hand, the patient's high expectations are on indicators of fast and straightforward patient registration services (D1), the doctor always asks about the patient's complaints (D4), the doctor gives the opportunity to ask the patient (D5), the doctor provides an explanation of the patient's disease (D6), and doctors provide actions in accordance with applicable procedures (D7). This is supported by high reality so that it shows that the RSGM Nala Husada UHT is able to provide good registration service procedures and doctor professionalism to patients. Therefore, the four indicators must be maintained because the performance of the servants can meet the level of patient satisfaction at RSGM Nala Husada UHT.

While the officer indicator provides information about clear treatment procedures (D2), the officer is alert in serving patients (D3), the doctor communicates effectively (D9), and the officer communicates effectively (D10) shows low patient expectations and low reality. This shows that the UHT Nala Husada Dental Hospital patients do not have high expectations about the alertness and effective communication from doctors and staff of the UHT Nala Husada Hospital. For this reason, it is necessary to process information regarding the importance of good communication with patients, so that it can increase satisfaction with services at UHT Nala Husada Hospital.

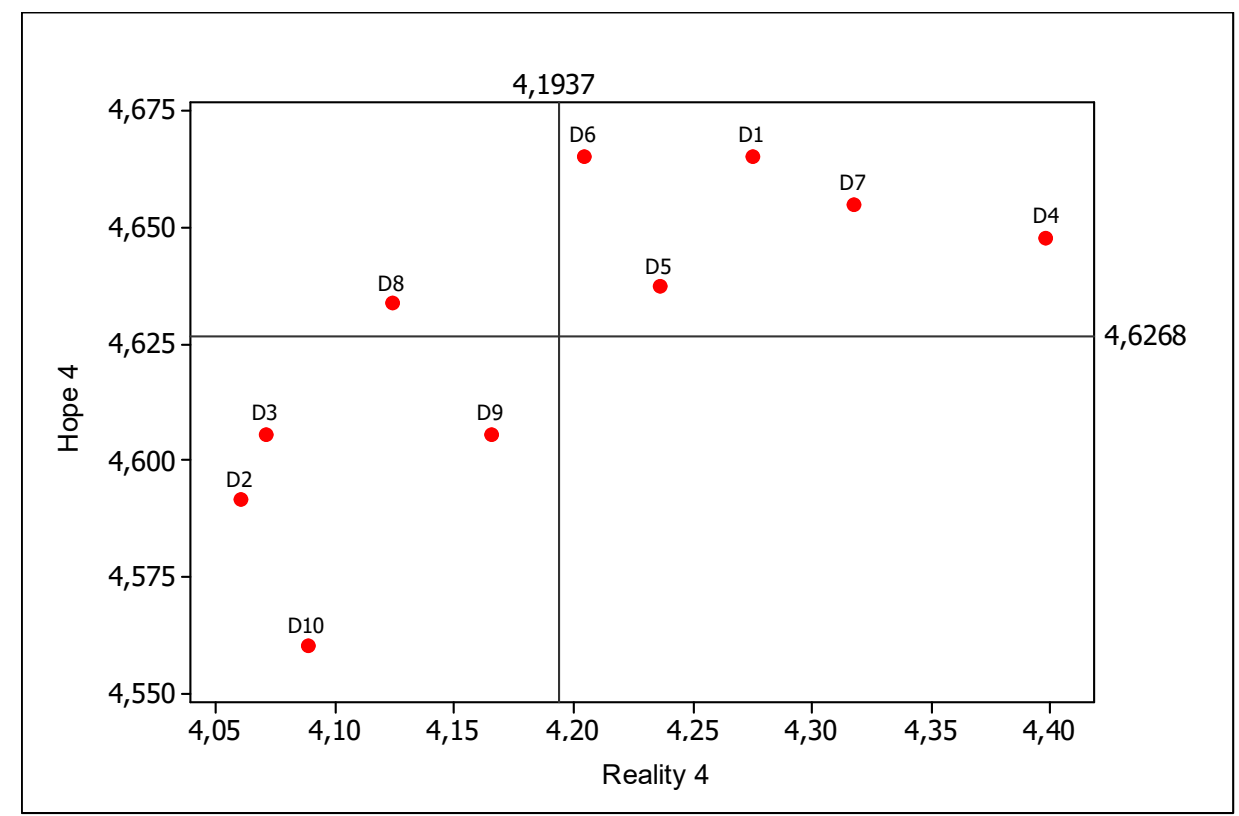

Figure 10. GAP Analysis on Responsiveness / Accuracy Dimensions

f. GAP Analysis on the Dimension of Assurance / Assurance that Affects Patient Satisfaction at the UHT Nala Husada Hospital in 2019

In the dimension of Assurance at RSGM Nala Husada UHT is measured through 10 indicators consisting of parking space security, patient comfort and safety for services from doctors, patient satisfaction with doctors / officers who maintain confidentiality and the ability of doctors to answer and provide good explanations regarding patient's disease. GAP analysis on the Assurance dimension can be explained in Figure 12.

Indicators that need to be the focus of the RSGM Nala Husada UHT to be improved are indicators of safe parking (E1), patient comfort when consulting with doctors (E2), the ability of doctors to provide good explanations about the patient's illness / to patient questions
(E6) , and the doctor's ability to answer and provide explanations to patient questions (E7). This is shown by the high patient expectations on these four indicators, but in reality what was obtained from the RSGM Nala Husada UHT was low.

While the indicators that have been able to meet patient satisfaction at UHT Nala Husada Hospital in the dimension of accuracy are doctors maintaining patient data confidentiality (E3), officers maintaining patient confidentiality (E4), doctors through knowledge and skills regarding patient complaints (E5), and doctors are able to explain the usefulness how to use drugs to patients (E8). This is shown through high expectations of the skills of doctors and officers at UHT Nala Husada Hospital, and supported by high reality, so that the level of patient satisfaction with these four 
indicators has been fulfilled and needs to be maintained by the UHT Nala Husada Hospital.

Patients who have low expectations of the doctor's indicator fill in the medical record book (E9) and the doctor is able to provide health education to patients (E10). However, the reality from the UHT Nala Husada Hospital is also low. This shows that the patient does not yet know the importance of filling in medical books and health education from doctors, so it is necessary to periodically inform the importance of these indicators.

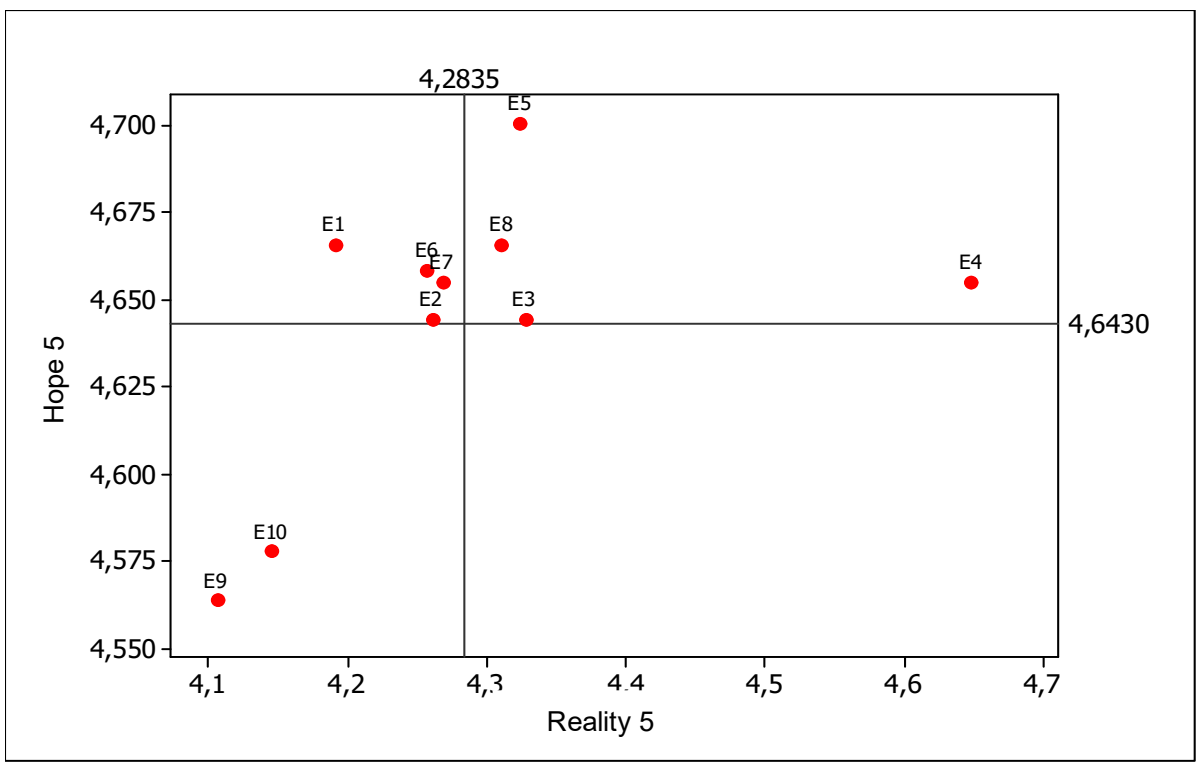

Figure 11. GAP Analysis on the Assurance Dimension

g. GAP Analysis on Patient Satisfaction Indicators that Affect Patient Satisfaction at UHT Nala Husada Hospital in 2019

After doing GAP analysis on the five dimensions used to measure the level of patient satisfaction at the UHT Nala Husada Hospital. Furthermore, an analysis is carried out on the satisfaction indicator consisting of 29 questions. The results of the analysis can be explained in Figure 12.

Figure 12 shows the results of the GAP analysis on patient satisfaction indicators which in quadrant I the patient has high expectations for the UHT Nala Husada Hospital in the form of UHT Nala Husada Hospital services that match patient expectations (F1), patient satisfaction with the services provided (F2), patients who have never felt disappointed with the services provided (F3), high willingness of medical personnel to serve patients (F8), fast handling of complaints from the UHT Nala Husada Hospital (F13), UHT Nala Husada Dental Hospital is better than other health institutions ( F16), UHT Nala Husada Dental Hospital has adequate and complete poly, the reputation of UHT Nala Husada Hospital is quite good in the eyes of the community (F18). However, the low reality was obtained by a patient from the UHT Nala Husada Hospital. 


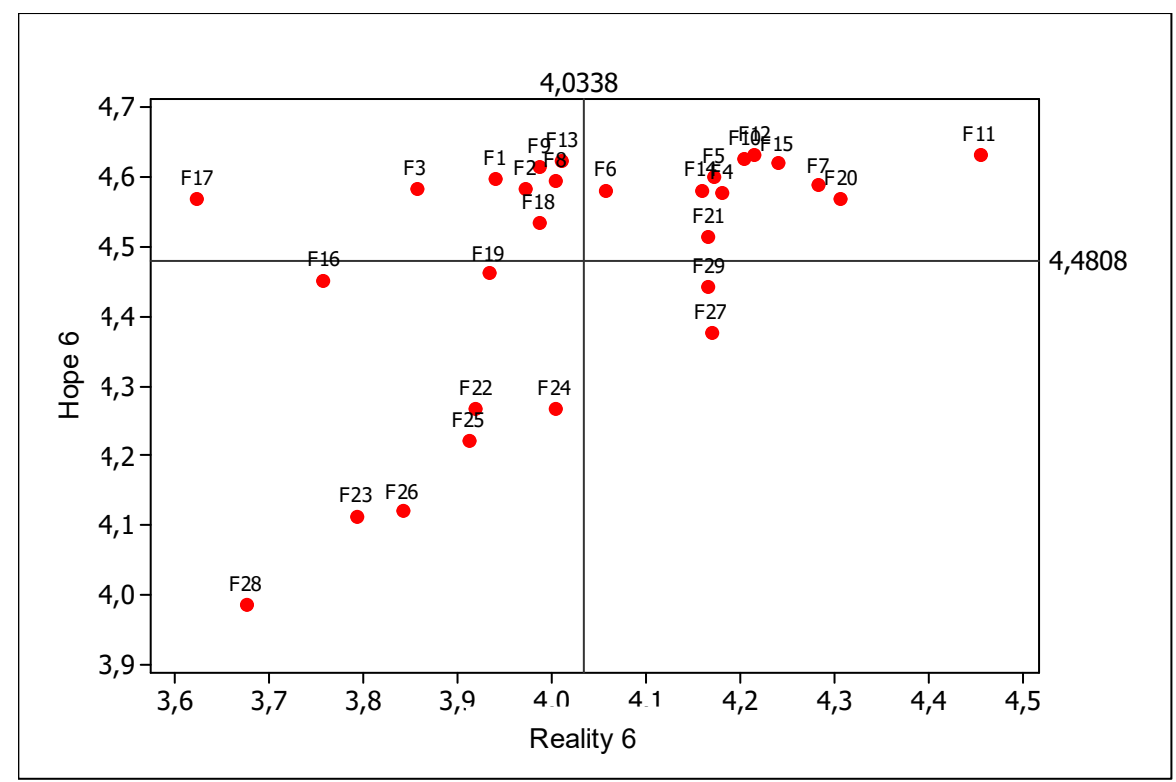

Figure 12. GAP Analysis on Patient Satisfaction Indicators

While the indicators of satisfaction that need to be maintained by RSGM Nala Husada UHT in order to meet patient satisfaction include indicators of patient satisfaction with the facilities and infrastructure at UHT Nala Husada Hospital (F4), Nala Husada Hospital UHT is a trusted health institution (F5), RSGM Nala Husada UHT knows how to provide good service to patients (F6), RSGM Nala Husada UHT plays an appropriate role as a health institution (F7), there are no treatment errors experienced by patients (F10), RSGM Nala Husada UHT listens to patient complaints well (F12), patients get a fair solution in handling complaints (F14), officers treat politely to patients who submit complaints (F15), the overall comparison of the rates charged is more affordable (F20), and RSGM Nala Husada UHT is the patient's first choice in doing treatment (F21). This is shown by the high patient expectations of these indicators, and supported by the high reality given by the UHT Nala Husada Dental Hospital so that patient satisfaction has been fulfilled.

The indicator in quadrant III is the low expectation of the UHT Nala Husada Hospital patient and the reality given to the patient is also low. These indicators include the UHT Nala Husada Hospital is better than other health institutions (F16), the patient feels impressed with the services provided by the UHT Nala Husada Hospital (F19), the patient has a sense of commitment to the UHT Nala Husada Hospital (F22), The patient feels lost if there is no UHT Nala Husada Hospital (F23), If someone asks for advice, the patient will recommend the Nala Husada UHT Hospital (F24), the patient tells the advantages of the UHT Nala Husada Hospital (F25), the patient encourages family / friends to take medication at RSGM Nala Husada UHT when sick, and patients believe that RSGM Nala Husada UHT is a good health institution (F29).

Quadrant I is the main priority that needs to be addressed which has high expectations, but the reality given by the RSGM Nala Husada UHT is actually low. In the satisfaction analysis, the main priorities that need to be addressed are the services provided by the UHT Nala Husada Hospital (F1), Patient satisfaction with the services of the UHT Nala Husada Hospital (F2), Patient disappointment with the services of the UHT Nala Husada Hospital (F3), the level of willingness of medical personnel in caring for patients (F8), assistance of UHT Nala Husada Hospital officers to patients (F9), speed of handling complaints of patients at UHT Nala Husada Hospital (F13), completeness of poly at UHT Nala Husada Hospital (F17), and Reputation of UHT Nala Husada Hospital in the eyes of the public (F18)

\section{CONCLUSION}

From the research results it can be concluded that:

a. The results of the validity and reliability tests of the core survey show that all indicators are valid. The characteristics in the core survey results show that on average the respondents are women, with the type of work being Student / Student.

b. GAP analysis on patient satisfaction data at RSGM Nala Husada UHT shows that the instruments that must be maintained are the dimensions of Empathy, Responsiveness, and Assurance. Meanwhile, the dimension that needs improvement is Reliability. In the Tangible dimension, the indicators that must be 
improved are satisfaction regarding the signposts and the adequacy of the number of doctors. In the Empathy dimension, the indicator that needs to be improved is the staff's friendliness instrument in serving patients. Whereas in the Reliability dimension, there are no instruments that need to be improved, the responsiveness dimension that needs to be improved is the speed and accuracy of doctors in handling patients, and the indicators in the Assurance dimension that need to be improved are parking facilities and the ability of doctors.

\section{ACKNOWLEDGEMENT}

The authors greatly acknowledge the support from Naval Technology College, STTAL Surabaya Indonesia for providing the necessary resources to carry out this research work. The authors are also grateful to Hang Tuah University, UHT Surabaya, Indonesia who always give me opportunity to improve my research. And the last the authors would like to say thank to the anonymous reviewers and journal editorial board for their many insightful comments, which have significantly improved this article.

\section{REFERENCES}

Adi, S. 2015. Gap Analysis. https://sis.binus.ac.id/2015/07/28/gapanalysis-analysis-kes Gap/.

Aryani, D., \& Rosinta, F. (2010). Effect of Service Quality on Customer Satisfaction in Forming Customer Loyalty. Journal of Administrative and Organizational Sciences Vol. 17 No. 2, 114-115.

Dharma, A. 2016. Statistical Analysis on Customer Satisfaction of Pertalite Fuel Users in Sidoarjo with Binary Logistic Regression Approach and GAP Analysis. Thesis Undergraduate Statistics Study Program, Mathematics Department, UNAIR.

Febriyanto. 2011.Expectation and Performance Gap Analysis based on Visitor Perceptions of Way Kambas National Park in East Lampung. East Lampung College of Economics.

Griffin, J., \& Lowenstein, MW (2001). Customer Winback: How to Recapture Lost Customers and Keep Them Loyal. New York: John Wiley \& Sons.

Gunawan, K., \& Djati, SP (2011). Service Quality and Patient Loyalty (Study at
General Hospital in Singaraja City-Bali). Bali.

Kotler, P. (2002). Marketing Management, Millenium Edition. United States of America: Pearson Custom Publishing.

Musanto, T. (2004). Factors of Customer Satisfaction and Customer Loyalty: Case Studies on CV. Media Advertising Facilities Surabaya. Journal of Management \& Entrepreneurship Vol. 6, No. 2, 128.

Parasuraman, A., Zeithaml, VA, \& Berry, LL (1988). SERVQUAL: A Multiple-Item Scale for Measuring Consumer Perceptions of Service Quality. Journal of Retailing Vol. 64 No. 1, 23.

Puspitasari, NB, \& Arifianty, MS (2016). The Effect of Service Quality on Patient Satisfaction on Complaints and Loyalty of Inpatients. Semarang.

Suharjana. (2012). Healthy Living Habits and Character Education Values. Journal of Character Education Year II No. 2, 191192.

Walpole, RE (1995). Introduction to Statistics 3rd Edition. Translated by: Sumantri. Jakarta: PT Gramedia Pustaka Utama.

Wendha, AA, Rahyuda, IK, \& Atmosphere, IG (2013). The Effect of Service Quality on Customer Satisfaction and Loyalty of Garuda Indonesia in Denpasar. Journal of Management, Business Strategy, and Entrepreneurship Vol. 7 No. 1, 19-22.

Wijayanto, I., \& Iriani, SS (2013). The Influence of Brand Image on Consumer Loyalty. Journal of Management Science Vol. 1 No. 3, 913. 